\title{
Effect of Saturation on Dynamic Soil Properties in Low Strain Range Using Resonant Column Apparatus
}

\author{
Pali Bhave, B. K. Maheshwari \\ Indian Institute of Technology Roorkee \\ Roorkee, India \\ Pali8.peq2016@iitr.ac.in; Bkmahfeq@iitr.ac.in
}

\begin{abstract}
The paper presents results on dynamic soil properties from laboratory testing by using resonant-column apparatus. It is used to measure the properties in low strain range. The resonant column testing is based on the determination of the resonant frequency of a soil specimen by measuring the specimen response at different excitation frequencies. The dynamic soil properties such as shear modulus, elastic modulus, Poisson's ratio and damping ratios are presented discussed and compared. The various soil parameters such as relative density, confining pressures are considered. Also the effect of saturation on above properties (shear modulus, elastic modulus, Poisson's ratio, and damping ratio) is examined. From this the results of dry and saturated samples are compared. The tests are conducted at confining pressures $(50 \mathrm{kPa})$ and relative densitiy $(30 \%)$. From this the results of dry and saturated samples are compared.
\end{abstract}

Keywords: Shear Modulus, Damping Ratio, Dynamic Properties, Resonant Column, Shear Strain, Specimen.

\section{Introduction}

The nature of earthquake loading will be greatly influenced by response of soils given by cyclic loading. This response is controlled by mechanical properties of soil. The mechanical properties associated with dynamic loading are shear wave velocity (Vs.), shear modulus (G), damping ratio (D), and Poisson's ratio (n) given by Kramer [1] . Soils exhibit nonlinear shearing stress-shearing strain behaviour as the strain level increases from nearly elastic to plastic conditions. For important problems, those dominated by wave propagation effects, only low levels of strain are induces in the soil. For those involving stability of masses of soils large strains are induced in the soil. The behaviour of soils subjected to dynamic loading is governed by Dynamic soil properties. A wide variety of field and laboratory tests are available with certain advantages and disadvantages. Different tests are done based on the required specifications. They are high strain and low strain tests in both field testing and laboratory testing. Field tests allow measurement of soil properties in situ, so that the existing natural conditions of soils such as chemical, thermal, and structural conditions remains same. Dynamic soil properties are those properties which are made through measurement of soils. Hence the evaluation of dynamic soil property is of utmost importance. Sharma and Maheshwari [8] (2016) have investigated that degree of saturation significantly influences the dynamic soil properties, therefore these properties also have effect of water content. The main purpose is to study the behaviour of soils (Solani sand) at different strain levels using resonant column apparatus for both dry and saturated samples. The resonant column test is used to evaluate dynamic moduli and damping values of soils at certain strain range $(0.001 \%$ to $0.1 \%)$. Anderson and stoke [4] (1978) have determined shear modulus at low shearing strain. Field tests also measure the response of large volumes of soil and induce soil deformation similar to those induced by earthquakes. And it does not allow measurement of the behaviour of the soil u1nder stress states or soil conditions. Low strain tests include seismic reflection, seismic 10 refraction, steady state vibration, spectral analysis of surface waves, seismic cross hole test, and seismic cone tests. The other important parameters which influence the dynamic properties of cohesive soil are effective confining pressure, shear strain and plasticity index of the soil. Other factors which influence the dynamic properties of cohesive soil but its influence is found to be less significant are frequency of loading, number of loading cycles, void ratio, degree of saturation, over consolidation ratio, grain characteristics etc. a series of resonant column tests were performed on compacted cohesive soil to determine its dynamic properties. Madhusudhan [7] (2011) has conducted a series of resonant column tests in torsional mode of vibration to assess the effect of saturation on damping of sands. Low strain test usually operates at strain levels that are not large enough to induce significant nonlinear stress-strain 
behaviour at shear strains below about $0.001 \%$.It is based on theory of wave propagation in linear materials. Seed and Wong [5] (1986) have evaluated the response of soil deposits and determined its modulus and damping ratios. High strain test include standard penetration test (SPT), cone penetration test (CPT), dilatometer test, and pressure meter test. The low strain tests are used to determine the property in-situ condition. The resonant column test determines the dynamic soil properties of various soil samples. (Hardin [3] 1965; Drnevich et al.[10] (1978) Drnevich[11] (1978).Hardin and Music [2] (1965) have evaluated the properties at high strain using cyclic triaxial test. Das and Bhownik [9] (2017) has investigated the effect of saturation on dynamic soil properties of sand.

\section{Methodology}

The methodology of Kumar and Madhusudhan [6] (2010); is used to find the elastic modulus of the sample from resonant frequency. The basic principle of the resonant column test is to vibrate a cylindrical soil specimen in a fundamental mode of vibration, in torsion or flexure. Once the fundamental mode is established, measurements of resonant frequency and amplitude of vibration are made. The drive system consists of a four-arm rotor that had a permanent magnet fitted to the end of each arm and a support cylinder. For torsional vibrations all the four pairs of coils were used whereas for flexural vibrations only two pairs of coils are used to produce force. The frequency can be controlled of applied voltage and the resonant frequency can be determined. The output from the accelerometer is amplified by means of a charge amplifier. The computer will be connected to the signal generator, charge amplifier, and LVDT(linearly variable displacement transducer).

The equipment has a standard cell capable of applying pressures upto1 $\mathrm{MPa}$, and has an electromagnetic drive system consisting of coils and magnets. The system has an internal LVDT for measurement of sample deformation, an internal mounted counter-balanced accelerometer and a drive amplifier for driving the system and a high speed 16-bit data acquisition and control card with interface panel.

\section{Test Analysis and Results}

It provides evaluation of parameters of dynamic soil properties. The torsional and damping tests were carried out for Solani sand.The specifications are $50 \mathrm{~mm}$ diameter and $100 \mathrm{~mm}$ height. The sample was prepared by wet tamping method for different relative density at $30 \%$,. The variation of soil with respect to different relative densities can be determined. Confining pressure are used i.e., $50 \mathrm{kPa}$. From these the stiffness characteristics and damping characteristics are determined. The input is given in terms of voltages. $(0.001$ to $0.5 \mathrm{~V})$.

\subsection{Effect of Saturation at $\mathrm{RD}=30$}

The tests are performed on both flexure and torsional mode. The tests are performed on saturated samples and its results are being compared with the results of dry sample.

\subsubsection{Torsion Test}

Given below shows the variation of shear modulus and damping ratio with shear strain .It can be observed that the stiffness (shear modulus) decreases with increase in shear strain, whereas the damping ratio of soil increases with increase in shear strain. The variation of shear modulus with shear strain is because of the reduction in stiffness of soil with increase in shear strain. The damping ratio increases with increase in shear strain because of more slippage of soil particle causes more dissipation of energy at higher strain.Figure 1 show the variation of shear modulus with shear strain at $\mathrm{RD}=30 \%$, and $\mathrm{CP}=50 \mathrm{kPa}$.It can be seen that from figure that shear modulus for dry specimen is $8.6 \%$ more than that of saturated sample. It can be clearly seen from figure 2 that no significant effect can be compared between dry and saturated sample at same $\mathrm{RD}(30 \%)$ and same confining pressures $(50 \mathrm{kPa})$. 


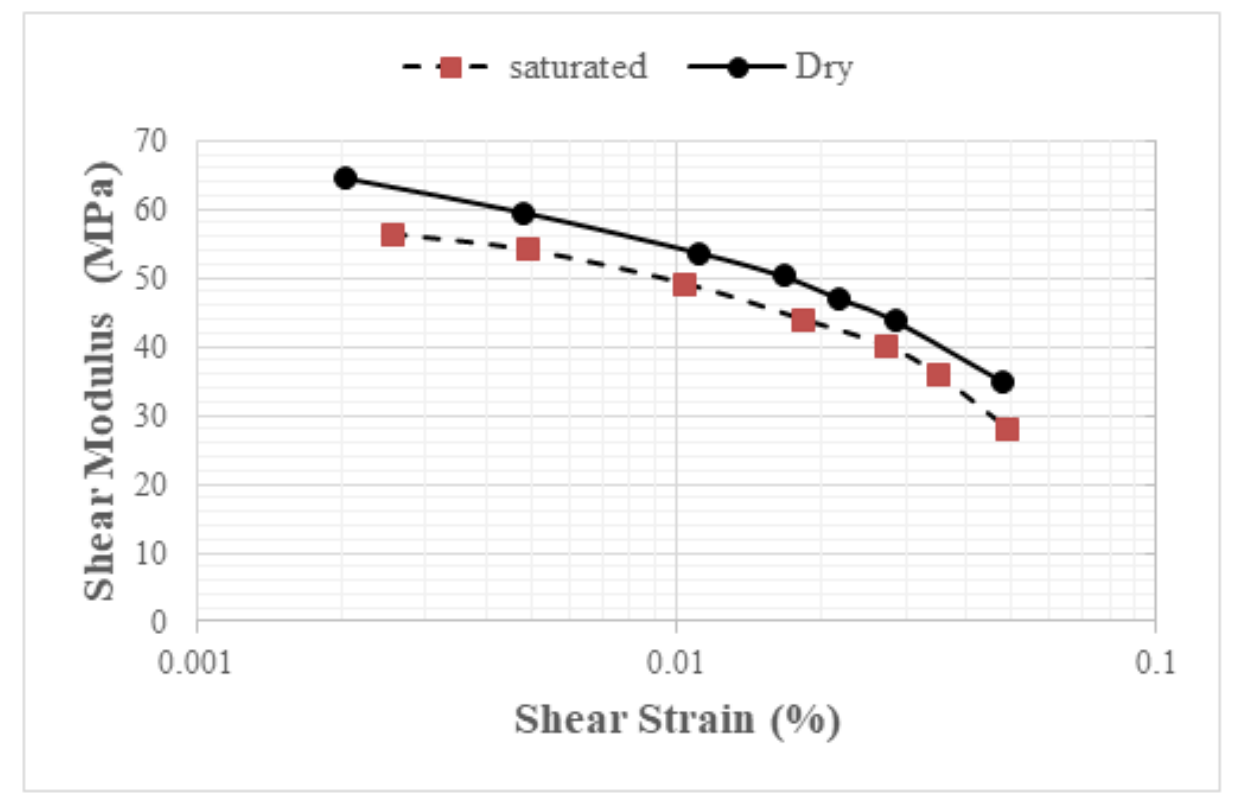

Fig. 1: Variation of shear modulus with shear strain.

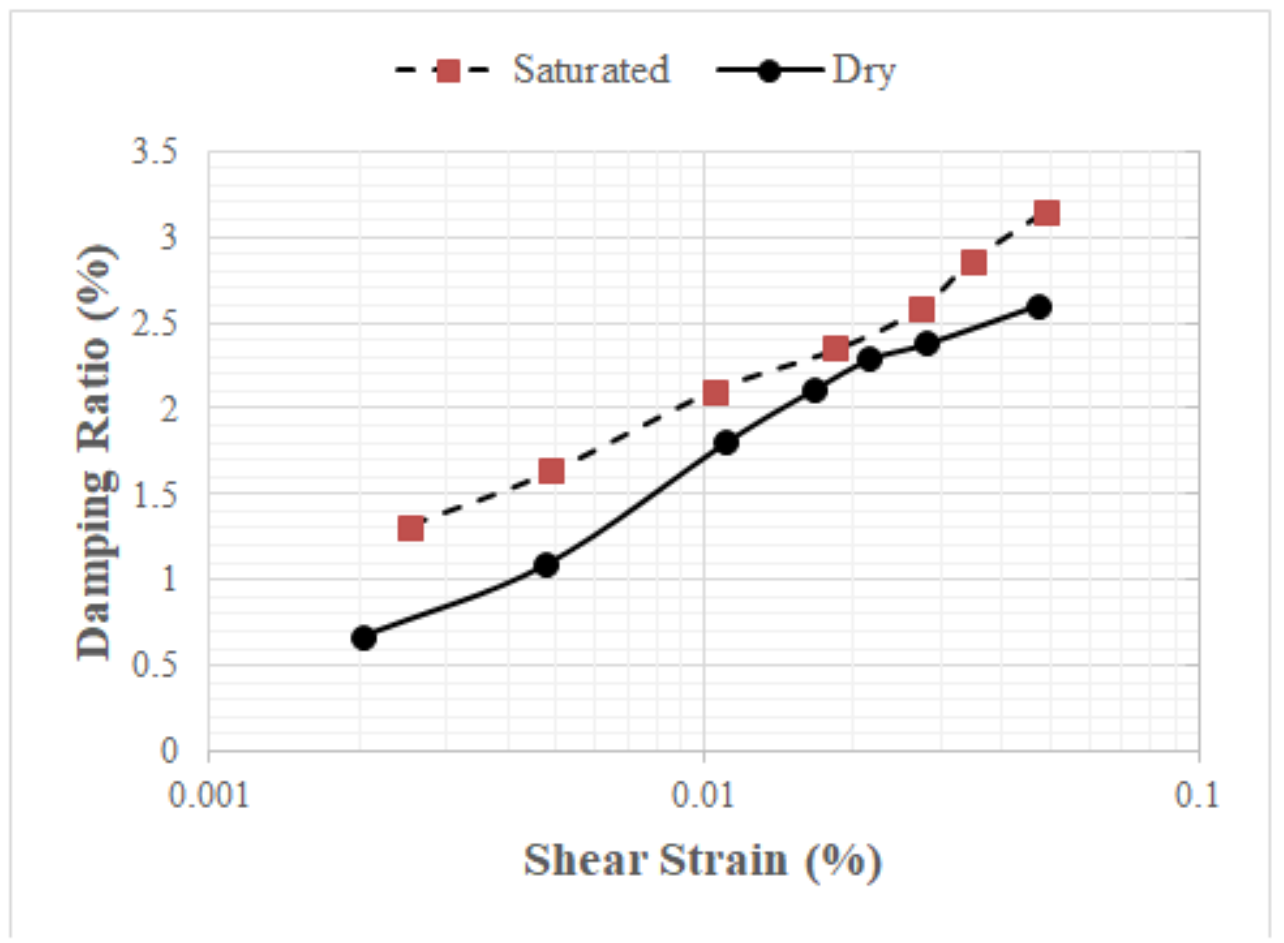

Fig. 2: Variation of damping ratio with shear strain.

\subsubsection{Flexure Test}

Given below shows the variation of modulus of elasticity of soil and damping ratio with axial strain .It is seen that modulus of elasticity of soil decreases with increase in axial strain and this decrease in modulus of elasticity is more at higher strain. The modulus of elasticity of soil sample is found to be higher than shear modulus of the sample.Figure 
3 shows variation of modulus of elasticity with axial strain at $\mathrm{RD}=30 \%$, and $\mathrm{CP}=50 \mathrm{kPa}$. It can be seen from figure 3 that modulus of elasticity is more for dry specimen than saturated specimen. The modulus of elasticity is 0.142 time more than saturated sample.Figure 4 shows variation of damping ratio with axial strain. The damping ratio of soil increases with axial strain.Figure 5 shows the variation of Poisson's ratio with axial strain.The Poisson's ratio of soil increases with increase in axial strain.

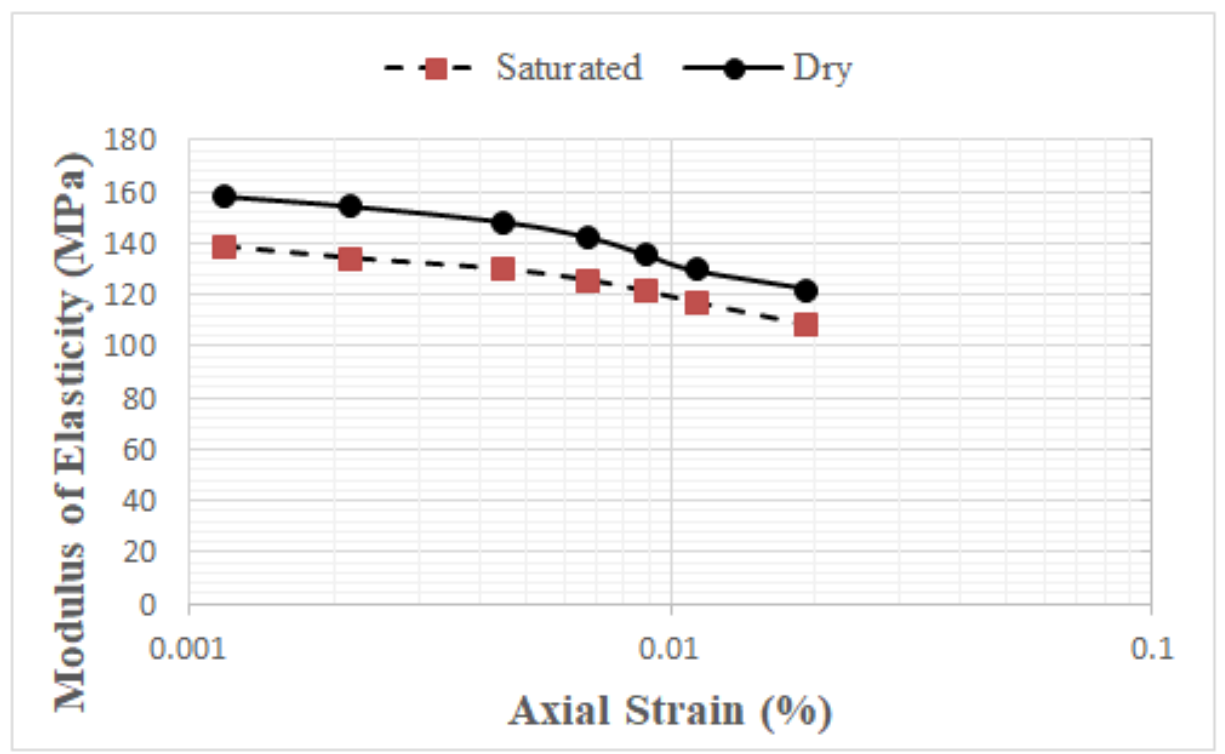

Fig. 3: Variation of elastic modulus with axial strain.

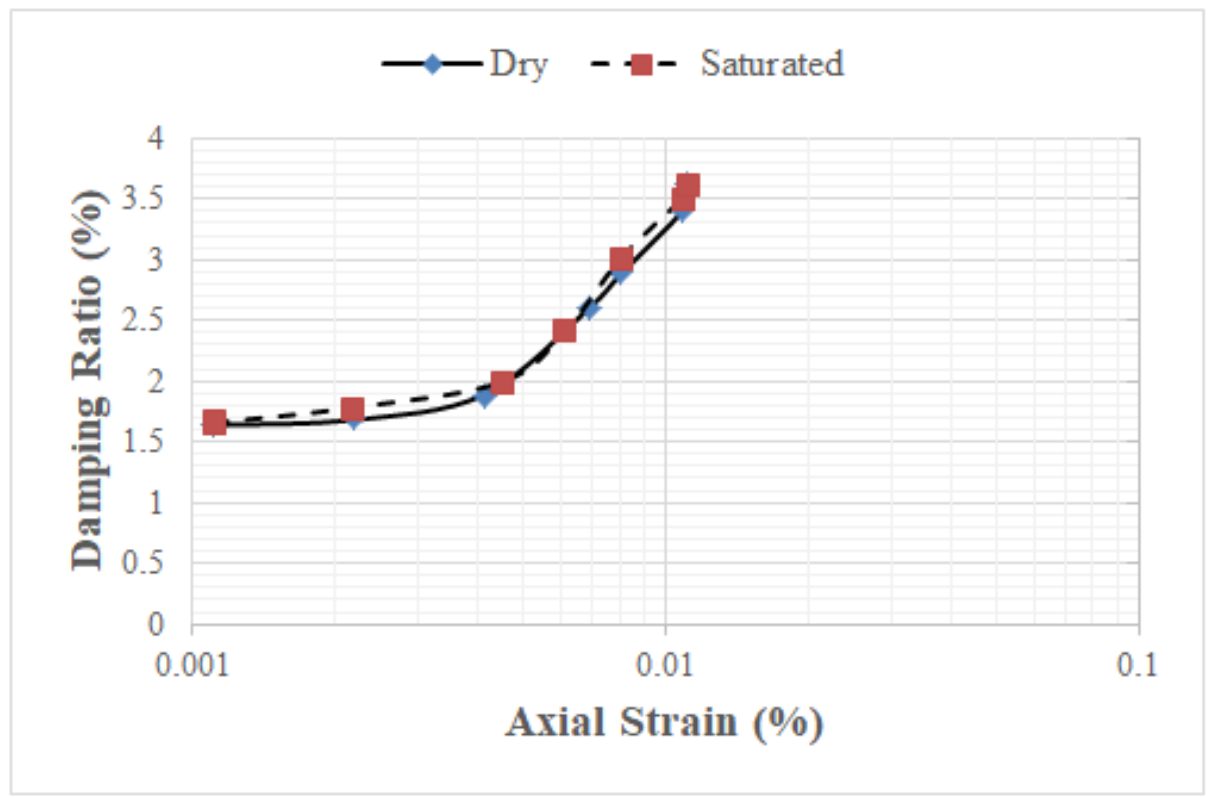

Fig. 4: variation of damping ratio with shear strain. 


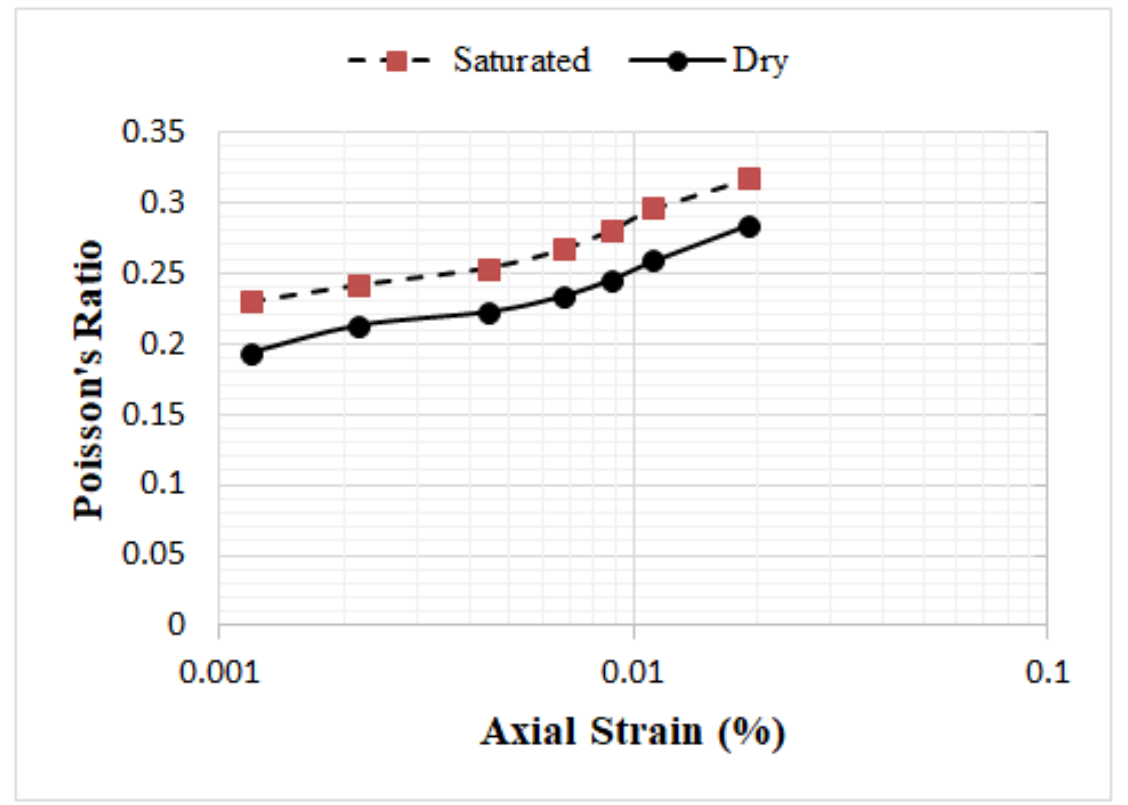

Fig. 5: Variation of Poisson's ratio with axial strain.

\section{Conclusions}

Based on the following laboratory test conditions on dry and saturated samples at different relative density and confining pressures at low strain level conditions, following conclusions can be drawn

The shear modulus and modulus of elasticity decreases with increase in shear strain.These occurs due to the reduction in stiffness of soil. The damping ratio of sand increases with increase in strain. The damping ratio increases with increase in shear strain because of more slippage of soil particle causes more dissipation of energy at higher strain. The shear modulus is more for dry specimen than that of saturated samples. The modulus of elasticity of dry specimen is more than that of saturated specimen.The damping ratio is more for saturated specimen as compared to dry specimen.The Poisson's ratio is more for saturated specimen as compared to dry specimen

\section{References}

[1]. S. L. Kramer, Geotechnical Earthquake Engineering. Ed. Hall. W. J Pearson Education, first Indian print, 2003.

[2]. B. O. Hardin and J. Music, "Apparatus for Vibration of soil specimens during the Triaxial Test," J. Instruments and apparatus for soil and rock mechanics., vol. ASTM STP 392, pp. 55-74, 1965.

[3]. B. O. Hardin, "The nature of damping in sands," J. Soil mechanics and foundations division., vol. 91, no. SM1, pp. 63-95, 1965.

[4]. D. G. Anderson and K. H. Stokoe II, "Shear Modulus: A Time-Dependent soil property," J. Dynamic Geotechnical Testing., vol. ASTM STP 654, pp. 66-90, 1978.

[5]. H. B. Seed and R. T. Wong. "Moduli and Damping factors for dynamic analyses of cohesionless soil," $J$. Geotechnical Engineering., vol. 112, no. 11, pp. 1016-1032, 1986.

[6]. J. Kumar and B. N. Madhusudhan. "On determining the elastic modulus of a cylindrical sample subjected to flexural excitation in a resonant column apparatus," J. Can Geotech., vol. 47, pp. 1288-1298, 2010.

[7]. B. N. Madhusudhan, "Dynamic properties of dry to fully saturated states using resonant column and bender element tests," Ph.D. Dissertation, Dept. Civil. Eng., Indian Institute of science, Bangalore, India.

[8]. P. Sharma and B.K. Maheshwari, "Effect of saturation on dynamic properties of solani sand," in the Proceedings of Indian Geotechnical Conference IGC, IIT Madras, India, pp. 1-4, 2016. 
[9]. S. Das and D. Bhowmik, "Effect of Saturation on Dynamic Properties of Barak River Sand at Small Strain Condition," in the Proceedings of National Conference on Recent Advancement in Geotechnical Investigation and Ground Improvement Technique, Silchar, India, vol. 1, no. 1, 2017.

[10]. V. P. Drnevich B. O. Hardin and D. J. Shippy, "Modulus and damping of soils by the Resonant-Column method," J. Dynamic Geotechnical Testing., vol. ASTN STP 654, pp. 91-125, 1978.

[11]. V. P. Drnevich, "Resonant-Column testing-problems sand solutions." J. Dynamic Geotechnical Testing., vol. ASTM STP 654, pp. 384-398, 1978. 